\title{
One Health Perspectives on Emerging Public Health
} Threats

\author{
Sukhyun Ryu ${ }^{1,2}$, Bryan Inho Kim², Jun-Sik Lim ${ }^{3,4}$, Cheng Siang Tan ${ }^{5}$, Byung Chul Chun ${ }^{2}$ \\ ${ }^{1}$ Division of Infectious Disease Control, Gyeonggi Provincial Government, Suwon; ${ }^{2}$ Department of Epidemiology and Medical Informatics, School of \\ Public Health, Korea University, Seoul; ${ }^{3}$ Disease Diagnostic Team, Gyeonggi Livestock and Veterinary Service, Suwon; ${ }^{4}$ Department of Epidemiology, \\ School of Public Health, Seoul National University, Seoul, Korea; ${ }^{5}$ Centre for Tropical and Emerging Diseases, Faculty of Medicine and Health Sciences, \\ Universiti Malaysia Sarawak, Sarawak, Malaysia
}

Antimicrobial resistance and emerging infectious diseases, including avian influenza, Ebola virus disease, and Zika virus disease have significantly affected humankind in recent years. In the premodern era, no distinction was made between animal and human medicine. However, as medical science developed, the gap between human and animal science grew deeper. Cooperation among human, animal, and environmental sciences to combat emerging public health threats has become an important issue under the One Health Initiative. Herein, we presented the history of One Health, reviewed current public health threats, and suggested opportunities for the field of public health through better understanding of the One Health paradigm.

Key words: One health, Zoonoses, Antibiotic resistance, Infectious disease, Korea

\section{INTRODUCTION}

Increasing antimicrobial resistance (AMR) and emerging zoonotic pathogens, including avian influenza, Ebola virus, and Zika virus have threatened global health. These novel public health threats are urgent issues, because $61 \%$ of infectious organisms affecting humans are zoonotic [1]. Therefore, a heightened awareness has emerged of the need to address health issues through health management at the interfaces of human health, animal health, and environmental health. One Health is defined as an integrative effort of multiple disciplines working

Received: June 29, 2017 Accepted: October 3, 2017

Corresponding author: Byung Chul Chun, MD, PhD

73 Inchon-ro, Seongbuk-gu, Seoul 02841, Korea

Tel: +82-2-2286-1169, Fax: +82-2-927-7220

E-mail: chun@korea.ac.kr

This is an Open Access article distributed under the terms of the Creative Commons Attribution Non-Commercial License (http://creativecommons.org/licenses/bync/4.0/) which permits unrestricted non-commercial use, distribution, and reproduction in any medium, provided the original work is properly cited. locally, nationally, and globally to achieve optimal health for people, animals, and the environment, and it has been proposed as a paradigm through which such interdisciplinary collaboration can be introduced and encouraged [2]. To overcome the recent threats posed by AMR and emerging zoonotic diseases, it is becoming clear that the entire health system must address the One Health concept. The purpose of this article is to introduce the One Health paradigm and to describe how it is deeply related with the recent public health threats.

\section{HISTORY OF ONE HEALTH}

The concept of One Health is based on the historical concept of comparative medicine. In the premodern era, the purpose of studying animals was to extrapolate knowledge about animals to understand human medicine; thus, there was no dividing line between human and animal medicine. An 18th-century physician, Vicq d'Azyr, was one of the true forefathers of comparative medicine. At his time, rinderpest, a fatal infectious 
disease in cattle, was widespread in Europe. Vicq d'Azyr linked human and animal epidemics to climatic and geographical conditions through the study of rinderpest [3]. In the 19th century, the first modern veterinary educational institutions were established. Still, animal medicine and human medicine were not strictly separated, and research was conducted into these 2 fields without the presence of strict disciplinary boundaries. At the time, veterinary schools and medical schools had a system that allowed their students to attend each other and study both types of medicine without distinction. In fact, this was recommended. Furthermore, most professors of early veterinary schools were physicians of human medicine. Although the systems of medical and veterinary schools were completely separated at the end of the 19th century, physicians' interest in animals persisted [3]. They used the term 'comparative' when studying animals, and considered animal research to be a field of medicine. In the modern era, the epidemiologist William Foege, who played a major role in eradicating smallpox, said "You can't tell the story of human health separate from animal health or environmental health" [4]. In 1975, the World Health Organization (WHO), the Office International des Epizooties, and the Food and Agriculture Organization of the United Nations collaboratively defined the concept of veterinary public health, which was an important facilitator of the international response to avian influenza in 2003 [5].

One Health, which started with comparative medicine and then went through the paradigm of One Medicine before including environmental health, calls for a horizontal approach across interdisciplinary institutions and requires a contextual approach to ecosystems.

\section{ANTIMICROBIAL RESISTANCE IN THE ONE HEALTH PERSPECTIVE}

The total number of food-producing animals, including cattle, pigs, poultry, and goats, in the Republic of Korea (hereafter Korea) is approximately 20 million, and $950000 \mathrm{~kg}$ of antibiotics was used in 2015 alone [6]. During the extended period of antibiotic exposure in animals that is used as a growth promoter, the bacteria in animals develop resistance, which can be transmitted to humans directly or indirectly [7]. Thus, the containment of AMR is not only an issue involving humans.

In August 2016, the Korean government established a new 5-year AMR action plan. Despite the 10 years of previous efforts of the Korean National Antimicrobial Resistance Safety
Control Program, which operated between 2003 and 2013, the prevalence of antimicrobial resistance in humans remains high, and is still increasing for pathogens such as Streptococcus pneumoniae and methicillin-resistant Staphylococcus aureus. The lack of knowledge about the appropriate use of antibiotics in medical and veterinary practices, as well as incomplete surveillance, can be considered a main cause of the increasing trend of AMR in Korea [8]. Integrated strategies drawing on the One Health concept were applied in this new Korean action plan, primarily to reduce the selection pressure of antimicrobial use in both human and veterinary sectors. However, a significant knowledge gap still exists in terms of AMR in humans versus in animals. Thus, this knowledge gap should be reduced by obtaining scientific evidence through further research and exchanging knowledge between sectors.

\section{AVIAN INFLUENZA IN THE ONE HEALTH PARADIGM}

An outbreak of highly pathogenic avian influenza (HPAl) H5N6 occurred in Gyeonggi Province, Korea in September 2016. Previous laboratory studies showed that HPAI H5 viruses from poultry were not well adapted to humans. However, China has reported HPAI H5N6 infections in humans and domestic cats, which is alarming. HPAI H5N6 poses a threat to humans and mammalian animals [9]. To remove the potential threat of the human transmission of the H5N6 virus, the Korean government conducted mass culling operation in poultry farms infected with HPAI H5N6. Approximately 37 million poultries were culled and 25000 people participated in the depopulation in Gyeonggi Province alone. Active surveillance of exposed persons, including those who had personal protective equipment, with antiviral prophylaxis during the depopulation activities was conducted. To date, a single domestic cat on an infected poultry farm was found to be infected with HPAI H5N6 and no human cases have been reported in Korea.

To reduce the socioeconomic burden of emerging zoonotic diseases, including the current outbreak of HPAI H5N6 in poultry, it is necessary to address the importance of surveilling animals and their breeding environment, with the goal of promoting the early detection of zoonotic diseases and limiting their transmission. Furthermore, communications between medical and veterinary professionals should be promoted, so that they not only share their knowledge, but also collaborate in joint researches. 


\section{GEOGRAPHICAL EXPANSION OF EMERGING INFECTIOUS DISEASES}

The Ebola virus disease (EVD) epidemic in West Africa between 2014 and 2016 resulted in 28652 human cases and 11325 deaths [10]. This number is almost up to 10 times that of all previously reported EVD cases combined. The 2014-2016 EVD outbreaks involved an unprecedented spread of Ebola virus across Guinea, Liberia, and Sierra Leone and the initial spread across countries was facilitated with partially due to dense populations and the highways of the affected countries.

In addition to EVD, the mosquito-borne arbovirus Zika virus was first isolated from a febrile primate in Uganda in 1949, but the first human case was only reported 7 years later in Nigeria. Zika virus crossed to another continent, and a Public Health Emergency of International Concern was declared by the WHO after its introduction to poor urban areas in Brazil in 2016.

These examples indicate that the same pathogen can lead to completely different outcomes based on environmental conditions, and underscore the fact that it is extremely hard to predict these outcomes without considering environmental factors. The problem is that environments are tremendously diverse, so we need more research into the effects of environmental factors on infectious disease dynamics. Thus, environmental factors are essential for estimating the extent to which infectious diseases will spread, and they must be considered in any analysis of infectious diseases.

\section{CONCLUSION}

The general concept of One Health is widely accepted. However, multi-sectoral cooperation in the surveillance and control of emerging infectious diseases is challenging to achieve due to the significant gap between the fields of animal and human health. To reduce this gap, the European Union and US have provided funding to support interdisciplinary research within the One Health approach, such as research on interventions for emerging zoonotic diseases and early warning systems of threats to humans from animals. Given its importance for mitigating the public health threat from emerging infectious diseases and current international trends, the implementation of the One Health approach through multi-sectoral cooperative initiatives should be continuously discussed.

\section{CONFLICT OF INTEREST}

The authors have no conflicts of interest associated with the material presented in this paper.

The opinions expressed by the authors of this article do not necessarily reflect the opinions of the Gyeonggi Provincial Government.

\section{ORCID}

Sukhyun Ryu https://orcid.org/0000-0002-8915-8167 Bryan Inho Kim https://orcid.org/0000-0002-1798-5315 Jun-Sik Lim https://orcid.org/0000-0003-4645-2347 Cheng Siang Tan https://orcid.org/0000-0001-6312-4551 Byung Chul Chun https://orcid.org/0000-0001-6576-8916

\section{REFERENCES}

1. Taylor LH, Latham SM, Woolhouse ME. Risk factors for human disease emergence. Philos Trans R Soc Lond B Biol Sci 2001; 356(1411):983-989.

2. World Health Organization. One health; 2017 [cited 2017 Oct 23]. Available from: http://www.who.int/features/qa/onehealth/en/.

3. Parent A. Felix Vicq d'Azyr: anatomy, medicine and revolution. Can J Neurol Sci 2007;34(1):30-37.

4. Foege WH. One world, one health, can we muddle through? [cited 2017 Jun 29]. Available from: http://www.oneworldonehealth.org/sept2004/presentations/eve_foege.html.

5. World Bank. People, pathogens, and our planet. Volume 1: towards a one health approach for controlling zoonotic diseases; 2010 [cited 2017 Oct 23]. Available from: http://siteresources.worldbank.org/INTARD/Resources/PPP_Web.pdf.

6. US Food and Drug Administration. The national antimicrobial resistance monitoring system; 2015 [cited 2017 Oct 23]. Available from: https://www.fda.gov/animalveterinary/safetyhealth/antimicrobialresistance/nationalantimicrobialresistancemonitoringsystem/.

7. Casewell M, Friis C, Marco E, McMullin P, Phillips I. The European ban on growth-promoting antibiotics and emerging consequences for human and animal health. J Antimicrob Chemother 2003;52(2):159-161.

8. Ryu S, Head MG, Kim Bl, Hwang J, Cho EH. Are we investing wisely? A systematic analysis of nationally funded antimicrobial resistance projects in Republic of Korea, 2003-2013. J 
Glob Antimicrob Resist 2016;6:90-94.

9. Yu Z, Gao X, Wang T, Li Y, Li Y, Xu Y, et al. Fatal H5N6 avian influenza virus infection in a domestic cat and wild birds in China. Sci Rep 2015;5:10704.
10. Mylne AQ, Pigott DM, Longbottom J, Shearer F, Duda KA, Messina JP, et al. Mapping the zoonotic niche of Lassa fever in Africa. Trans R Soc Trop Med Hyg 2015;109(8):483-492. 